Article

\title{
Effect of Oxygen Content on Current Stress-Induced Instability in Bottom-Gate Amorphous InGaZnO Thin-Film Transistors
}

\author{
Sungju Choi®, Jae-Young Kim, Hara Kang, Daehyun Ko, Jihyun Rhee, Sung-Jin Choi, \\ Dong Myong Kim and Dae Hwan Kim *
}

The School of Electrical Engineering, Kookmin University, Seoul 02707, Korea; sungjuchoi@kookmin.ac.kr (S.C.); kjp1486@kookmin.ac.kr (J.-Y.K.); hara3540@kookmin.ac.kr (H.K.); kdh9147@kookmin.ac.kr (D.K.); badagirs@kookmin.ac.kr (J.R.); sjchoiee@kookmin.ac.kr (S.-J.C.); dmkim@kookmin.ac.kr (D.M.K.)

* Correspondence: drlife@kookmin.ac.kr; Tel.: +82-2-2910-4872

Received: 10 August 2019; Accepted: 24 September 2019; Published: 26 September 2019

check for updates

\begin{abstract}
The effect of oxygen content on current-stress-induced instability was investigated in bottom-gate amorphous InGaZnO (a-IGZO) thin-film transistors. The observed positive threshold voltage shift $\left(\Delta \mathrm{V}_{\mathrm{T}}\right)$ was dominated by electron trapping in the gate insulator $(\mathrm{GI})$, whereas it was compensated by donor creation in a-IGZO active regions when both current flows and a high lateral electric field were present. Stress-induced $\Delta V_{T}$ increased with increasing oxygen content irrespective of the type of stress because oxygen content influenced GI quality, i.e., higher density of GI electron traps, as well as typical direct current (DC) performance like threshold voltage, mobility, and subthreshold swing. It was also found that self-heating became another important mechanism, especially when the vertical electric field and channel current were the same, independent of the oxygen content. The increased $\Delta \mathrm{V}_{\mathrm{T}}$ with oxygen content under positive gate bias stress, positive gate and drain bias stress, and target current stress was consistently explained by considering a combination of the density of GI electron traps, electric field relaxation, and self-heating-assisted electron trapping.
\end{abstract}

Keywords: a-IGZO TFT; current stress; oxygen content; instability; electron trapping; oxygen flow rate; donor creation

\section{Introduction}

Since amorphous InGaZnO (a-IGZO) thin-film transistors (TFTs) are used in active-matrix organic light-emitting diode (AMOLED) television manufacturing, their reliability under long-term current stress is an important and challenging issue [1]. Although a-IGZO TFTs have been successfully commercialized into display products, next-generation displays with higher resolution, higher brightness, and longer product lifetime will demand more stable device characteristics. In particular, current stress-induced instability must be analyzed systematically along with various bias conditions, i.e., various gate-to-source voltage $\left(\mathrm{V}_{\mathrm{GS}}\right)$ and drain-to-source voltage $\left(\mathrm{V}_{\mathrm{DS}}\right)$ conditions, because current-driving TFTs in an AMOLED pixel as well as the TFTs in gate-driver circuitry experience various $V_{G S}$ and $V_{D S}$ conditions during real operation of the display circuits. On the other hand, the performance or stability of a-IGZO TFTs has been widely designed and optimized based on controlling the oxygen content (O-content) in IGZO thin films [2-8]. Therefore, thoroughly understanding the effect of O-content in IGZO thin films on current stress (CS)-induced instability under various $\mathrm{V}_{\mathrm{GS}}$ and $\mathrm{V}_{\mathrm{DS}}$ conditions is indispensable for the design of highly stable a-IGZO TFTs as well as for the design of current-driving schemes for high frame-rate display backplanes [9]. However, consolidated explanations of the effect of O-content on various CS-induced instabilities in a single framework are rare. 
In this work, the effect of O-content on CS-induced instability is experimentally investigated in bottom-gate a-IGZO TFTs under various $\mathrm{V}_{\mathrm{GS}}$ and $\mathrm{V}_{\mathrm{DS}}$ conditions. To control the O-content in IGZO thin films, the oxygen flow rate (OFR) during the sputter deposition of the IGZO film is modulated. The OFR-dependent O-content is verified by X-ray photoelectron spectroscopy (XPS), which is consistent with previous studies [6-8]. Moreover, the measured current-voltage (I-V) and hysteresis characteristics as well as the experimentally extracted subgap density of states (DOS) in a-IGZO active films are combined. Self-heating and power consumption are considered by using technology computer-aided design (TCAD) simulation. The influence of O-content on the CS-instability in IGZO TFTs under various $\mathrm{V}_{\mathrm{GS}} / \mathrm{V}_{\mathrm{DS}}$ conditions is elucidated from material science and device physics perspectives.

\section{Experimental Procedure and Material Properties}

The fabrication of a-IGZO TFTs with a bottom-gate structure is described as follows. The first room temperature (RT) sputtered deposition of a-IGZO on a glass substrate and patterning of the molybdenum (Mo) gate were followed by plasma-enhanced chemical vapor deposition (PECVD) of $\mathrm{SiN}_{\mathrm{X}}$ and $\mathrm{SiO}_{2}$ at $370{ }^{\circ} \mathrm{C}$, which acted as a gate dielectric (the equivalent oxide thickness, $\mathrm{T}_{\mathrm{ox}}$, was $258 \mathrm{~nm}$ ). A $50 \mathrm{~nm}$-thick a-IGZO thin film was then deposited by direct current (DC) sputtering $(3 \mathrm{~kW})$ at room temperature (RT) in a mixed atmosphere of $\mathrm{Ar}(35 \mathrm{sccm})$ and $\mathrm{O}_{2}$ by modulating the OFR to produce O-poor (21 sccm), O-mid (42 sccm), and O-rich $(63 \mathrm{sccm})$ TFT devices. Next, an etch stopper $\left(\mathrm{SiO}_{X}\right)$ layer was deposited by PECVD at $150^{\circ} \mathrm{C}$. For the formation of the source/drain (S/D) electrodes, Mo was sputtered at RT. A passivation layer $\left(\mathrm{SiO}_{X}\right.$ and $\mathrm{SiN}_{X}$; each $100 \mathrm{~nm}$ thick) was subsequently deposited. Finally, the devices were annealed at $250{ }^{\circ} \mathrm{C}$ for $1 \mathrm{~h}$ in a furnace. The width $\left(\mathrm{W}_{\mathrm{ch}}\right)$ and length of the device channel $\left(\mathrm{L}_{\mathrm{ch}}\right)$ were 200 and $100 \mu \mathrm{m}$, respectively.

To check if the OFR modulated the O-content in IGZO active films, the XPS spectra of the devices were analyzed. Figure 1 shows the $O_{1 s}$ spectra of the IGZO films. The low-binding-energy component $\left(O_{L}\right)$ located at $530 \mathrm{eV}$ is usually attributed to $\mathrm{O}_{2}{ }^{-}$ions surrounded by $\mathrm{Zn}, \mathrm{Ga}$, and in atoms in the IGZO compound system. The middle binding-energy component $\left(O_{M}\right)$ centered at $531.5 \mathrm{eV}$ is associated with $\mathrm{O}_{2}{ }^{-}$ions that are in the oxygen-deficient regions of the IGZO matrix. Therefore, a change in the peak area ratio is related to the concentration of oxygen vacancies. $\mathrm{O}_{\mathrm{M}}$-related oxygen vacancies supply free electron carriers in the IGZO film, resulting in an increase of electron concentration. The high binding-energy component $\left(\mathrm{O}_{\mathrm{H}}\right)$ located at $532.4 \mathrm{eV}$ is mainly attributed to the presence of loosely bound, chemisorbed oxygen impurities $\left(-\mathrm{CO}_{3}{ }^{-}\right.$adsorbed $\mathrm{H}_{2} \mathrm{O}$ or adsorbed $\left.\mathrm{O}_{2}{ }^{-}\right)$on the surface of the film. The observed $O_{1 s}$ peak can be deconvoluted into three peaks, namely, $O_{L}, O_{M}$, and $O_{H}$, as shown in Equation (1), and their characteristic parameters are summarized in Table 1:

$$
O_{1 s}=O_{L}+O_{M}+O_{H}=N_{L} \cdot \exp \left(-\left(\frac{E-E_{L}}{k T_{L}}\right)^{2}\right)+N_{M} \cdot \exp \left(-\left(\frac{E-E_{M}}{k T_{M}}\right)^{2}\right)+N_{H} \cdot \exp \left(-\left(\frac{E-E_{H}}{k T_{H}}\right)^{2}\right)
$$

It is clearly observed in Figure 1 and Table 1 that $O_{M}$ decreases (from $33 \%$ to $28.5 \%$ ) and $O_{H}$ increases (from $5 \%$ to $11 \%$ ) as the OFR increases. The O-content is proportional to the OFR trend. The results of the XPS analysis suggest that the oxygen content in the IGZO film can be controlled by modulating the OFR during sputter deposition of the IGZO thin film. This is consistent with previous reports [6-8]. 


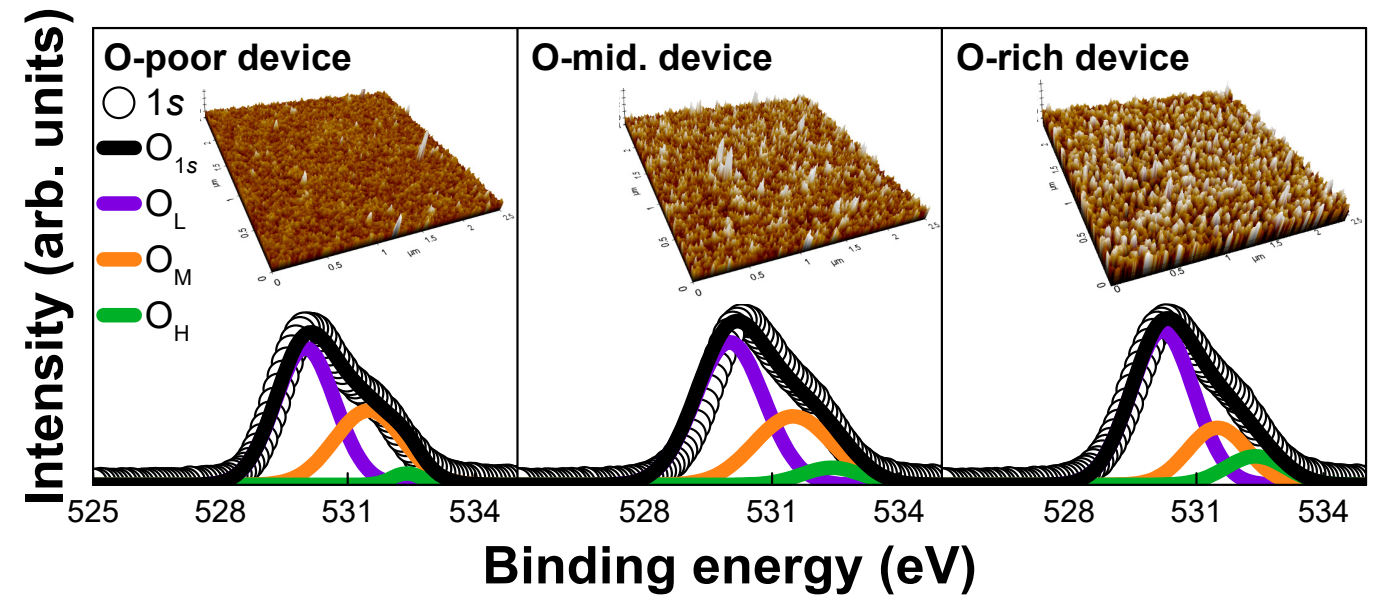

Figure 1. X-ray photoelectron spectroscopy (XPS) $O_{1 s}$ spectra of InGaZnO (IGZO) films upon varying the flow rate in a mixed atmosphere of $\mathrm{Ar}$ and $\mathrm{O}_{2}$ (oxygen flow rate $(\mathrm{OFR})=35 \mathrm{sccm}$ ). The OFR is modulated to produce O-poor (OFR = $21 \mathrm{sccm})$, O-mid $(42 \mathrm{sccm})$, and O-rich $(63 \mathrm{sccm})$ IGZO thin films. The inset shows the surface morphology of IGZO thin films as a function of OFR, as observed by atomic force microscopy (AFM).

Table 1. Extracted XPS parameters (initial).

\begin{tabular}{ccccc}
\hline \multicolumn{2}{c}{ O-Content } & O-Poor & O-Medium & O-Rich \\
\hline \multirow{6}{*}{$O_{L}$} & $N_{L}(\mathrm{~A} . \mathrm{U})$ & $1.20 \times 10^{5}$ & $1.25 \times 10^{5}$ & $1.30 \times 10^{5}$ \\
& $K T_{L}(\mathrm{eV})$ & & 1 & \\
& $E_{L}(\mathrm{eV})$ & & 530 & \\
& $N_{M}(\mathrm{~A} . \mathrm{U})$. & $0.65 \times 10^{5}$ & $0.60 \times 10^{5}$ & $0.50 \times 10^{5}$ \\
$O_{M}$ & $K T_{M}(\mathrm{eV})$ & 1.15 & 1.1 & 1.1 \\
& $E_{M}(\mathrm{eV})$ & & 531.5 & \\
& $N_{H}(\mathrm{~A} . \mathrm{U})$. & $0.10 \times 10^{5}$ & $0.2 \times 10^{5}$ & $0.25 \times 10^{5}$ \\
$O_{H}$ & $K T_{H}(\mathrm{eV})$ & 0.5 & 0.75 & 1 \\
& $E_{H}(\mathrm{eV})$ & & 532.4 & \\
\hline
\end{tabular}

The surface roughness of the IGZO films was characterized by using atomic force microscopy (AFM, Suwon, Republic of Korea), the results of which are presented in the inset of Figure 1. The measured roughness values for O-poor, O-mid, and O-rich devices were $0.236,0.386$, and $0.562 \mathrm{~nm}$, respectively. As the O-content becomes larger with increasing OFR, the IGZO surface becomes rougher.

The I-V characteristics of the IGZO TFTs were measured using an HP4156C (Keysight, Santa Rosa, CA, USA) semiconductor parameter analyzer at RT in the dark. The capacitance-voltage $(\mathrm{C}-\mathrm{V})$ characteristics were measured between the gate and the source tied to drain terminals by using an HP4294 LCR meter (Keysight, Santa Rosa, CA, USA). The subgap DOS was extracted using multi-frequency C-V spectroscopy [10], wherein frequencies of $2 \mathrm{kHz}, 100 \mathrm{kHz}$, and $1 \mathrm{MHz}$ were used with a ramp-up rate of $0.4 \mathrm{~V} / \mathrm{s}$ and a small signal of $0.1 \mathrm{mV}$.

In terms of the $\mathrm{V}_{\mathrm{GS}}$ and $\mathrm{V}_{\mathrm{DS}}$ conditions under $\mathrm{CS}$, three stress conditions were used during a stress time of $10^{4} \mathrm{~s}$ : positive gate bias stress (PGBS), where $\mathrm{V}_{\mathrm{GS}} / \mathrm{V}_{\mathrm{DS}}=20 / 0 \mathrm{~V}$; positive gate and drain bias stress (PGDBS), where $\mathrm{V}_{\mathrm{GS}} / \mathrm{V}_{\mathrm{DS}}=20 / 10 \mathrm{~V}$ regardless of the OFR; and target current stress (TCS) with $20 \mu \mathrm{A}$ for various O-contents, where $\mathrm{V}_{\mathrm{GS}} / \mathrm{V}_{\mathrm{DS}}=20 / 10 \mathrm{~V}$ for O-poor, 20.5/11 V for O-mid, and 22/12 $\mathrm{V}$ for O-rich. PGBS and PGDBS were investigated first, after which the TCS was analyzed. Here, TCS means that the $\mathrm{V}_{\mathrm{GS}} / \mathrm{V}_{\mathrm{DS}}$ condition varied depending on the $\mathrm{O}$-content, where $\mathrm{V}_{\mathrm{GS}}$ is determined so that the value of overdrive voltage $\left(\mathrm{V}_{\mathrm{GS}}-\mathrm{V}_{\mathrm{T}}\right)$ remains the same according to the O-content-dependent threshold voltage $\left(\mathrm{V}_{\mathrm{T}}\right)$. $\mathrm{V}_{\mathrm{DS}}$ is then determined such that the drain-to-source current $\left(\mathrm{I}_{\mathrm{DS}}\right)$ is maintained at the same value $(20 \mu \mathrm{A})$ as that of the O-poor TFT at $\mathrm{V}_{\mathrm{GS}} / \mathrm{V}_{\mathrm{DS}}=20 / 10 \mathrm{~V}$. Therefore, our TCS condition establishes both constant vertical electric field and constant current, at least in pristine states before CS. 


\section{Results and Discussion}

The O-content-dependent parameters of pristine TFT devices, such as I-V, $\mathrm{V}_{\mathrm{T}}$, subthreshold swing (SS), and saturation field-effect mobility $\left(\mu_{\mathrm{FE}}\right)$, are shown in Figure $2 \mathrm{a}-\mathrm{c}$, where $\mathrm{V}_{\mathrm{T}}$ was extracted by linear extrapolation. SS was determined from $10^{-10}$ to $10^{-9} \mathrm{~A}$ in the subthreshold region. In addition, $\mu_{\mathrm{FE}}$ was extracted using the square root method at $\mathrm{V}_{\mathrm{GS}}-\mathrm{V}_{\mathrm{T}}=10 \mathrm{~V}$ and $\mathrm{V}_{\mathrm{DS}}=10 \mathrm{~V}$. With increasing OFR, i.e., with higher O-content, $V_{\mathrm{T}}$ and $\mathrm{SS}$ increase, and $\mu_{\mathrm{FE}}$ decreases, as shown Figure $2 \mathrm{~b}, \mathrm{c}$. These results indicate that oxygen-related defects near the conduction band minimum $\left(\mathrm{E}_{\mathrm{C}}\right)$ increased with increasing OFR [11]. Therefore, the subgap DOS should be investigated to understand the effect of O-content on TFT performance and stability.
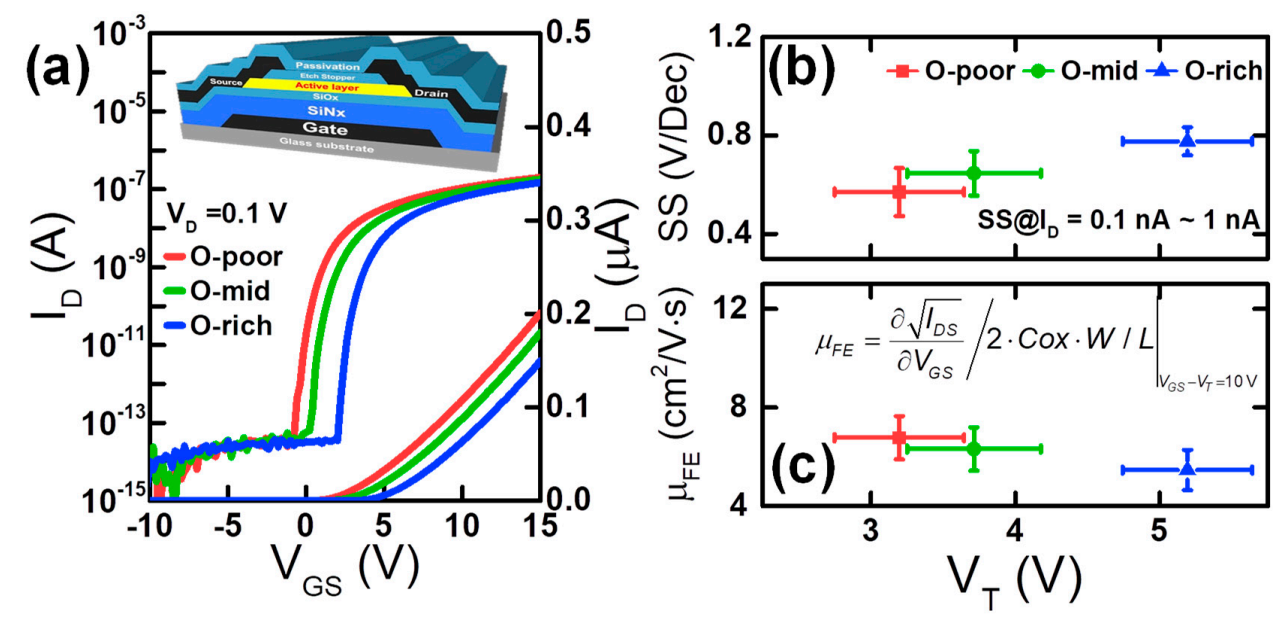

Figure 2. (a) $\mathrm{I}_{\mathrm{D}}-\mathrm{V}_{\mathrm{GS}}$ transfer curve characteristic at $\mathrm{V}_{\mathrm{DS}}=0.1 \mathrm{~V}$ for various $\mathrm{O}$-contents. The inset is the fabricated a-IGZO thin-film transistor (TFT) with an inverted staggered bottom-gate structure. The statistical data of (b) subthreshold swing (SS)- $\mathrm{V}_{\mathrm{T}}$, and (c) $\mu_{\mathrm{FE}}-\mathrm{V}_{\mathrm{T}}$ were extracted from 10 devices for each O-content.

The extracted DOS $(g(E))$ values near the $\mathrm{E}_{\mathrm{C}}$ were divided into three components according to their energy level distribution: 1. shallow donor-like states, characteristic, and center energies of the Gaussian peaks $\left(N_{S D}, k T_{S D}\right.$, and $\left.E_{S D}\right), 2$. acceptor-like deep states and characteristic $N_{D A}$ and $k T_{D A}$, and 3. tail states and characteristic $N_{T A}$ and $k T_{T A}$. The extracted $g(\mathrm{E})$ value near $E_{C}$ was modeled according to Equation (2):

$$
g(E)=g_{T A}(E)+g_{D A}(E)+g_{S D}(E)=N_{T A} \exp \left(-\frac{E_{C}-E}{k T_{T A}}\right)+N_{D A} \exp \left(-\frac{E_{C}-E}{k T_{D A}}\right)+N_{S D} \exp \left(-\left(\frac{E_{C}-E-E_{S D}}{k T_{S D}}\right)^{2}\right)
$$

The extracted DOS and their parameters are summarized in Figure 3 and Table 2. They were extracted for the initial state and after PGBS, PGDBS, and TCS.

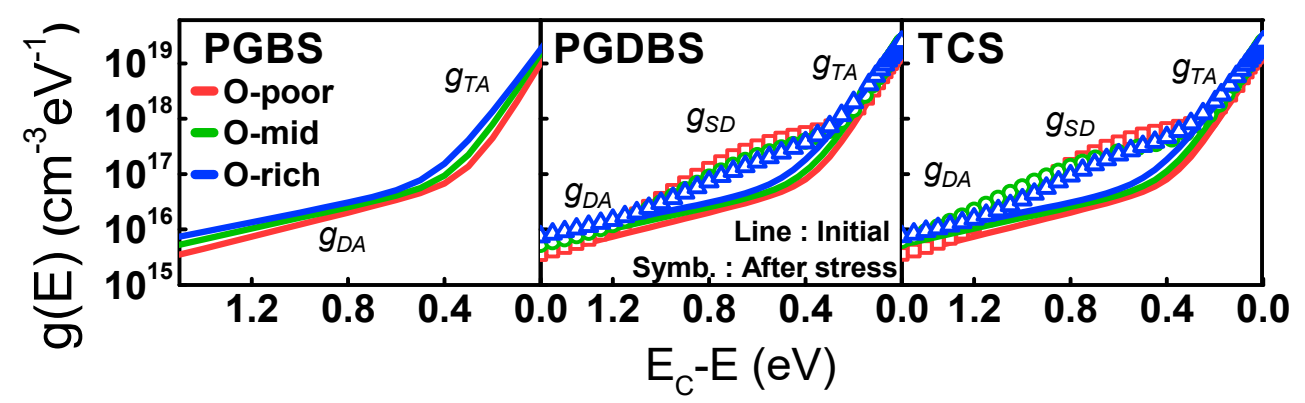

Figure 3. Density of states (DOS) over a range of O-content as stress time under positive gate bias stress (PGBS), positive gate and drain bias stress (PGDBS), and target current stress (TCS). Lines denote the initial state, and symbols indicate values after each stress condition. 
Table 2. Extracted DOS parameters (initial and after PGBS, PGDBS, and TCS).

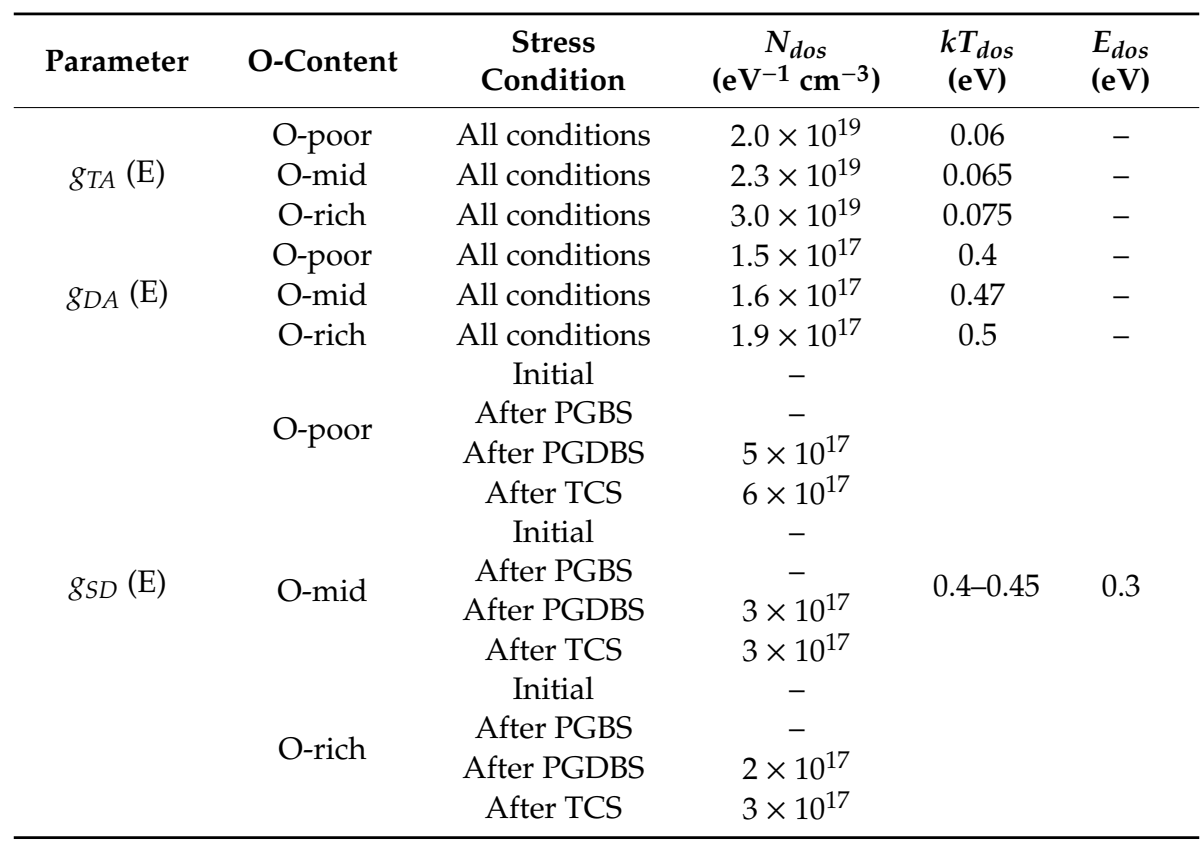

The effects of $\mathrm{O}$-content on $\mathrm{V}_{\mathrm{T}}$, SS, and $\mu_{\mathrm{FE}}$ (Figure $2 \mathrm{~b}, \mathrm{c}$ ) can be explained by considering both the XPS and AFM results (Figure 1) and the DOS (Figure 3). At first, $\mathrm{V}_{\mathrm{T}}$ increases as the O-content increases. This is explained by the decrease in the number of oxygen vacancies $\left(\mathrm{V}_{\mathrm{O}} \mathrm{s}\right)$ in the TFT devices with larger O-content, as shown in the XPS spectra in Figure 1. $\mathrm{V}_{\mathrm{O}}$ s are well-known shallow donors [12,13]. Second, SS increases with increasing O-content, which is explained by the higher $g_{T A}(E)$ and $g_{D A}(E)$ in the TFT devices with more O-content, as shown in Figure 3. Higher $g_{T A}(E)$ and $g_{D A}(E)$ result from an ion bombardment process during the sputter deposition with the increase of OFR [11]. Finally, $\mu_{\mathrm{FE}}$ decreases as the O-content increased, which can be explained as follows. In amorphous multi-metal oxides, some potential barriers are inherently present between neighboring ions at the $\mathrm{E}_{\mathrm{C}}$ and affect the electrons. Such barriers hinder electron transport and lower the mobility because of the different metal ion radii that result from the non-uniform overlap of conduction electron orbitals among $\mathrm{In}-\mathrm{O}, \mathrm{Ga}-\mathrm{O}$, and $\mathrm{Zn}-\mathrm{O}$ bonds [14]. Subsequently, the percolation barrier height is effectively lowered because of the higher Fermi energy $\left(\mathrm{E}_{\mathrm{F}}\right)$ in lower O-content or higher $\mathrm{V}_{\mathrm{GS}}$ conditions, thus leading to higher $\mu_{\mathrm{FE}}$. Moreover, the AFM topography of the sample shown in Figure 1 suggests that either the surface roughness scattering or trap density in IGZO increases for higher O-content, which is another reason for lower $\mu_{\mathrm{FE}}$.

It is usually reported that the electrical performance in IGZO TFTs is significantly affected by trap sites near the $E_{C}$ [11]. Several key parameters such as surface roughness, $g_{T A}(E), g_{S D}(E)$, and $g_{D A}(E)$ around the $\mathrm{E}_{\mathrm{C}}$ are both energetically and locally distributed throughout the energy bandgap with energy level dependency, causing carrier trapping and emission in each energy state (i.e., surface roughness scattering, multiple trapping, subgap hopping process, and thermal release events). Therefore, high trap density and high surface roughness decrease the mean free path of carriers and the ability to accumulate carriers, thus leading to the degradation of $\mu_{\mathrm{FE}}$ and SS.

The $\mathrm{I}_{\mathrm{DS}}-\mathrm{V}_{\mathrm{GS}}$ transfer characteristics before and after stress are shown in Figure 4 . The CS-induced $\mathrm{V}_{\mathrm{T}}$ shift $\left(\Delta \mathrm{V}_{\mathrm{T}}\right)$, which increased with O-content irrespective of the type of stress, is summarized in Figure 5. To clarify the degradation that occurred only in the a-IGZO active layer, $g(E)$ values before and after CS were also compared, as shown in Figure 3 and Table 2. Under the influence of PGBS and/or PGDBS, $\mathrm{V}_{\mathrm{T}}$ of the TFTs frequently shifted in the positive direction. The physical origin of PBTS instability has been classified largely by either electron trapping (e-trapping) into the gate insulator (GI) interface $[15,16]$ or the change in defect states in the active region [17]. In the former case, e-trapping 
becomes more accelerated with increasing temperature and/or electric field [18] as well as high density of electron traps in the gate insulator bulk interface. In the latter case, donor creation followed by a negative $\Delta V_{T}$ occurs, especially in short-channel TFTs $[19,20]$, whereas oxygen-dimer bond breaking was very recently observed as the physical origin of positive $\Delta \mathrm{V}_{\mathrm{T}}$ [21]. Furthermore, in comparison with PGBS, $\triangle \mathrm{V}_{\mathrm{T}}$ under PGDBS and/or TCS is very complicated because of various combinations of $\mathrm{V}_{\mathrm{GS}}$ and $\mathrm{V}_{\mathrm{DS}}$, and competition between e-trapping and donor creation has been reported [22].

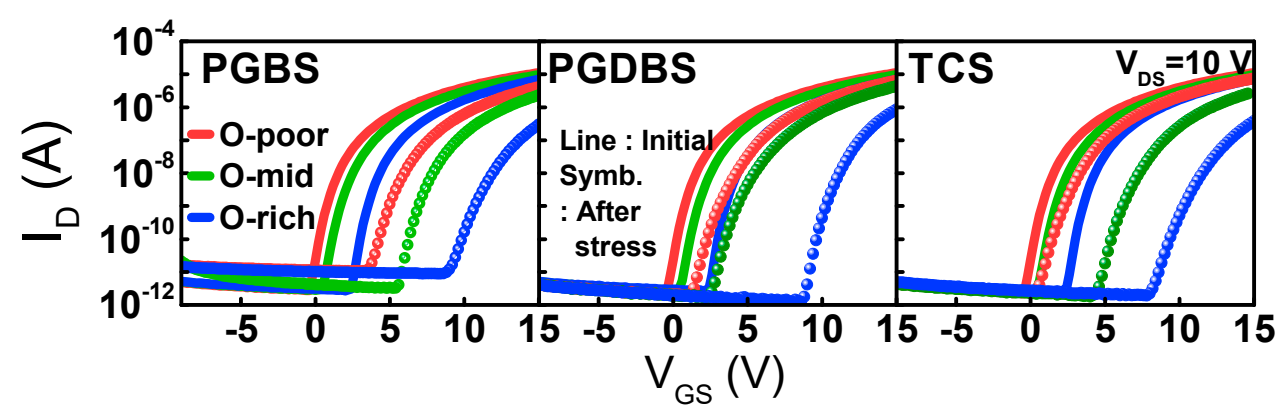

Figure 4. Transfer $\mathrm{V}_{\mathrm{GS}}-\mathrm{I}_{\mathrm{DS}}$ characteristics at $\mathrm{V}_{\mathrm{DS}}=10(\mathrm{~V})$ over a range of O-content as stress time under PGBS, PGDBS, and TCS. Lines denote the initial state, and symbols indicate values after each stress condition.

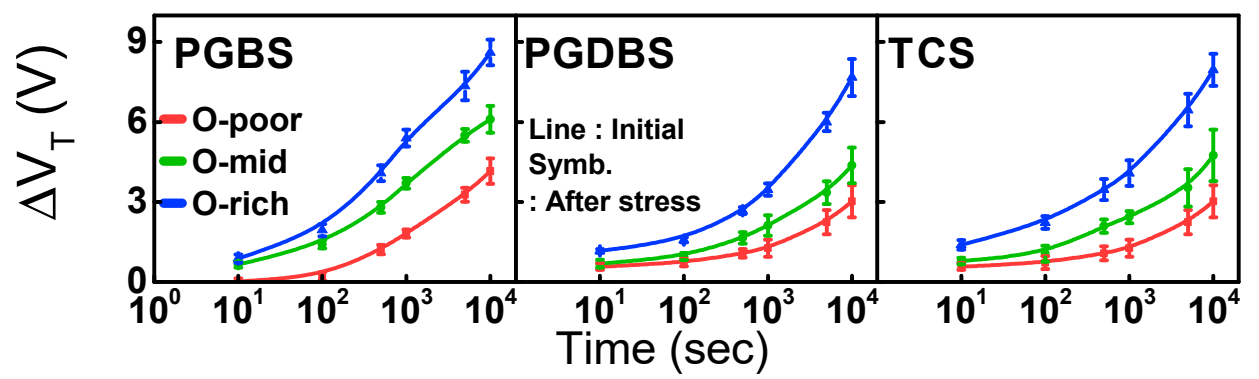

Figure 5. $\Delta \mathrm{V}_{\mathrm{T}}$ for various $\mathrm{O}$-contents as stress time under PGBS, PGDBS, and TCS.

Only under PGDBS and TCS, i.e., when $\mathrm{I}_{\mathrm{DS}}$ flowed through the channel, were shallow donor states consistently created below the $\mathrm{E}_{\mathrm{C}}$, as shown in Figure 3 and Table 2 . The physical origin of donor creation is still controversial. In this study, it seemed to be dominated by $\mathrm{V}_{\mathrm{O}}$ ionization [19] or by peroxide formation [23]. Under PGDBS or TCS, electrons gained enough energy from the lateral field and were able to break the weakest oxygen bond or generate holes. In the former case, $\mathrm{V}_{\mathrm{O}} \mathrm{s}$ that are not filled by electrons are generated by structure relaxation and are doubly positively charged $\left(\mathrm{V}_{\mathrm{O}^{2+}}{ }^{2+}[22]\right.$. In the latter case, hole-intermediated peroxide generation occurs, i.e., $\mathrm{O}^{2-}+\mathrm{O}^{2-} \rightarrow \mathrm{O}_{2}{ }^{2-}+2 \mathrm{e}^{-}$. In both cases, donor creation lowers $\mathrm{V}_{\mathrm{T}}$ when stress is applied. This is contradictory to the observed positive $\Delta \mathrm{V}_{\mathrm{T}}$. Therefore, the dominant mechanism behind the positive $\Delta \mathrm{V}_{\mathrm{T}}$ compensates donor creation (origin of a negative $\Delta \mathrm{V}_{\mathrm{T}}$ ), thus leading to eventual positive $\Delta \mathrm{V}_{\mathrm{T}}$. It can be assumed that the positive $\Delta \mathrm{V}_{\mathrm{T}}$ during stress originates from the e-trapping in the GI.

To validate our assumption, we examined the relationship between hysteresis and $\Delta \mathrm{V}_{\mathrm{T}}$, as shown in Figure 6a. The hysteresis effect is known to change $V_{T}$ when $V_{G S}$ is swept from negative to positive values and then the transfer curve is measured again while sweeping from positive to negative $V_{G S}$. That is, after accumulated carriers are trapped in shallow or deep traps of the GI, the captured carriers cause a screening effect to the $\mathrm{V}_{\mathrm{GS}}$. Therefore, the hysteresis voltage $\left(\mathrm{V}_{\mathrm{Hys}}\right)$ is a good indicator of the quality of the GI as well as the GI/IGZO interface. Here, $\mathrm{V}_{\mathrm{Hys}}$ is defined as the difference in $\mathrm{V}_{\mathrm{T}}$ between double $\mathrm{V}_{\mathrm{GS}}$ sweeps, i.e., the sweep from 20 to $-20 \mathrm{~V}$ and that from -20 to $20 \mathrm{~V}$ as denoted in Figure $6 \mathrm{a}$. Figure $6 \mathrm{a}$ indicates that the oxygen-content-dependent, PGBS-induced $\Delta \mathrm{V}_{\mathrm{T}}$ is well correlated with the $\mathrm{V}_{\mathrm{Hys}}$ depending on the O-content, which validates the assumption that the PGBS/PGDBS/TCS-induced instability is dominated by e-trapping in the GI and/or interface. 

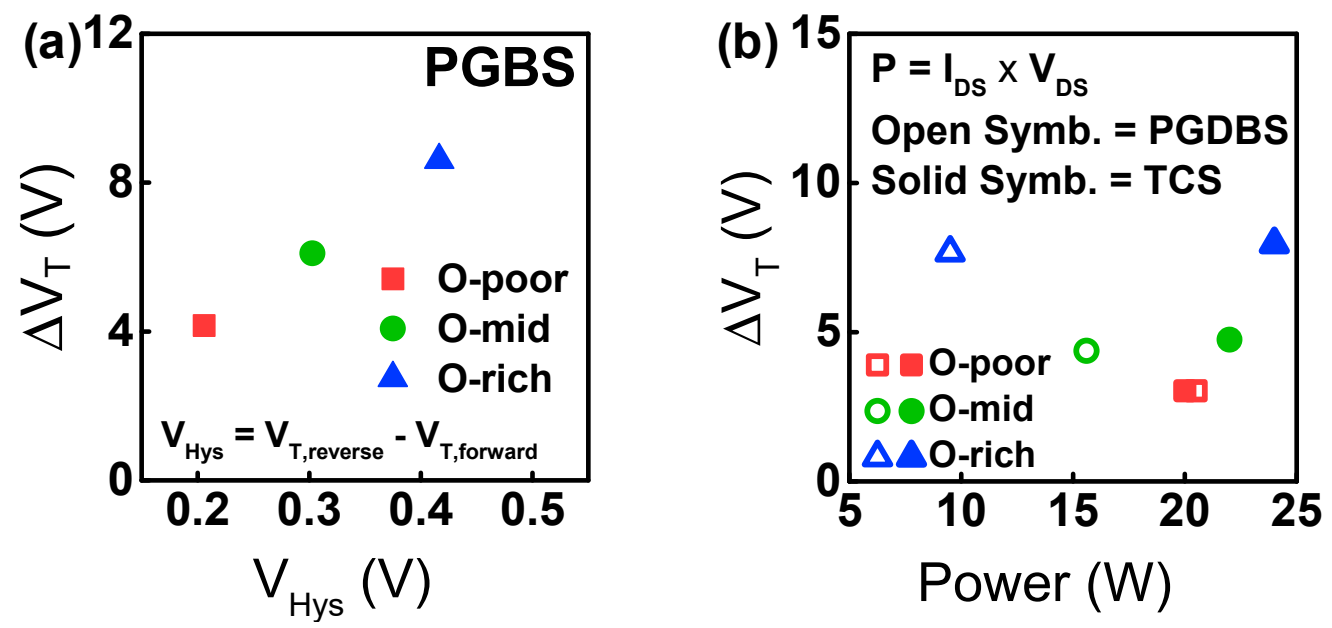

Figure 6. The OFR-dependent relationships (a) between $\Delta \mathrm{V}_{\mathrm{T}}$ and $\mathrm{V}_{\mathrm{Hys}}$ and (b) between $\Delta \mathrm{V}_{\mathrm{T}}$ and the average power consumption under PGDBS and TCS. Closed symbols denote PGDBS conditions, and open symbols indicate TCS conditions.

The effect of $\mathrm{O}$-content on $\Delta \mathrm{V}_{\mathrm{T}}$ and $\mathrm{V}_{\mathrm{Hys}}$ can be explained as follows. As the $\mathrm{O}$-content in the a-IGZO active layer increases, a larger number of oxygen atoms at the interface or in the active layer diffuse into the $\mathrm{SiO}_{2}$ of $\mathrm{GI}$ owing to the stronger $\mathrm{Si}-\mathrm{O}$ affinity in comparison to that of $\mathrm{Ga}-\mathrm{O}, \mathrm{Zn}-\mathrm{O}$, or $\mathrm{In}-\mathrm{O}(\mathrm{Si}-\mathrm{O}>\mathrm{Ga}-\mathrm{O}>\mathrm{Zn}-\mathrm{O}>\mathrm{In}-\mathrm{O})$ [24] during fabrication. Increased oxygen interstitials generate electron traps in the GI [25], which is consistent with relatively poor GI quality (i.e., larger $\Delta \mathrm{V}_{\mathrm{T}}$ ) and hysteresis in O-rich devices, as shown Figure 7 . Here, $\mathrm{N}_{\mathrm{OT}}$ symbolizes the spatial density of electron traps in the GI.

Given the O-content of the active layer, the positive $\Delta \mathrm{V}_{\mathrm{T}}$ increased in the following order: PGDBS $<$ TCS $<$ PGBS, as shown in Figure 5. In the PGBS condition, only e-trapping in the GI occurred effectively, both in the source and drain regions. However, in the PGDBS and TCS conditions, e-trapping near the drain was significantly alleviated, owing to the release of the vertical electric field and creation of donor states. Therefore, the largest positive $\Delta \mathrm{V}_{\mathrm{T}}$ occurred for PGBS conditions.
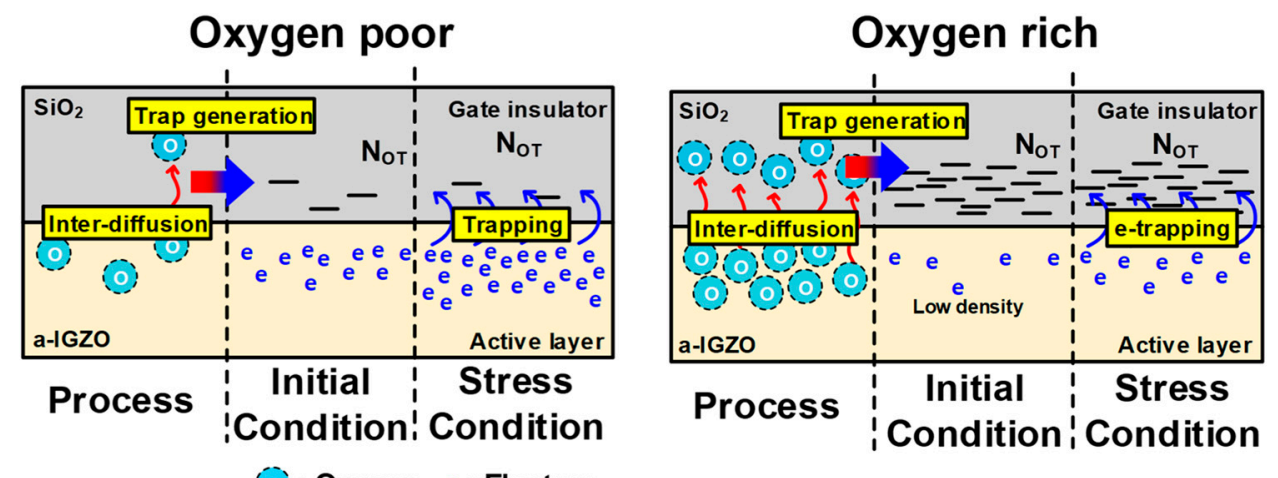

Figure 7. Production of electron trap centers according to O-content.

In addition, it should be noted that, for a given O-content, $\Delta \mathrm{V}_{\mathrm{T}}$ under TCS is larger than that under PGDBS. This can be explained by the self-heating assisted e-trapping [26-28], vertical electric field, and bulk oxide trap. To analyze the Joule heating effect under stress conditions, the average power consumption was calculated by multiplying the drain current by $\mathrm{V}_{\mathrm{DS}}$ under stress conditions, as shown in Figure $6 \mathrm{~b}$. Joule heating under TCS was greater than that under PGDBS. Such Joule heating accumulated from self-heating in the active layer as the thermal conductivity of a-IGZO is quite low [29]. E-trapping can then be activated to a greater extent via thermionic field emission-assisted GI 
trapping. Under PGDBS, although the O-poor device generated more heat in the active layer than that in the O-mid and O-rich devices, the $\Delta \mathrm{V}_{\mathrm{T}}$ of the O-rich device was the largest. These results indicate that e-trapping is dominated by the $\mathrm{N}_{\mathrm{OT}}$ rather than by the self-heating effect. Therefore, GI quality is the key factor for determining $\Delta \mathrm{V}_{\mathrm{T}}$ under TCS, PGDBS, and PGBS conditions for various O-contents. Self-heating-assisted e-trapping also becomes more significant for devices with the same O-content as the CS dissipates more Joule heating and power.

To validate our discussion, a well-calibrated TCAD simulation was performed by incorporating the energy band structure, a DOS model depending on the O-content, trap-limited conduction, and a self-heating model into Silvaco ATLAS-2D [30]. The electric field, Joule heating power, and device temperature were simulated under different conditions, as shown in Figure 8a-c. As shown in Figure $8 \mathrm{c}$, regardless of the O-content, self-heating was more significant in TCS than in PGDBS. Therefore, as shown in Figure $6 \mathrm{~b}$, the $\Delta \mathrm{V}_{\mathrm{T}}$ in TCS is larger than that in PGDBS irrespective of O-content. Here, it should be noted that, in the O-poor device, the TCS condition is the same as the PGDBS condition. Eventually, the CS-induced instability is determined by the increasing $\mathrm{N}_{\mathrm{OT}}$ with $\mathrm{O}$-content and the $\Delta \mathrm{V}_{\mathrm{T}}$-compensation by donor creation. Specifically, under TCS, the increasing self-heating with $\mathrm{O}$-content becomes another key factor, although both the initial vertical electric field and initial $\mathrm{I}_{\mathrm{DS}}$ are the same, independent of the O-content.
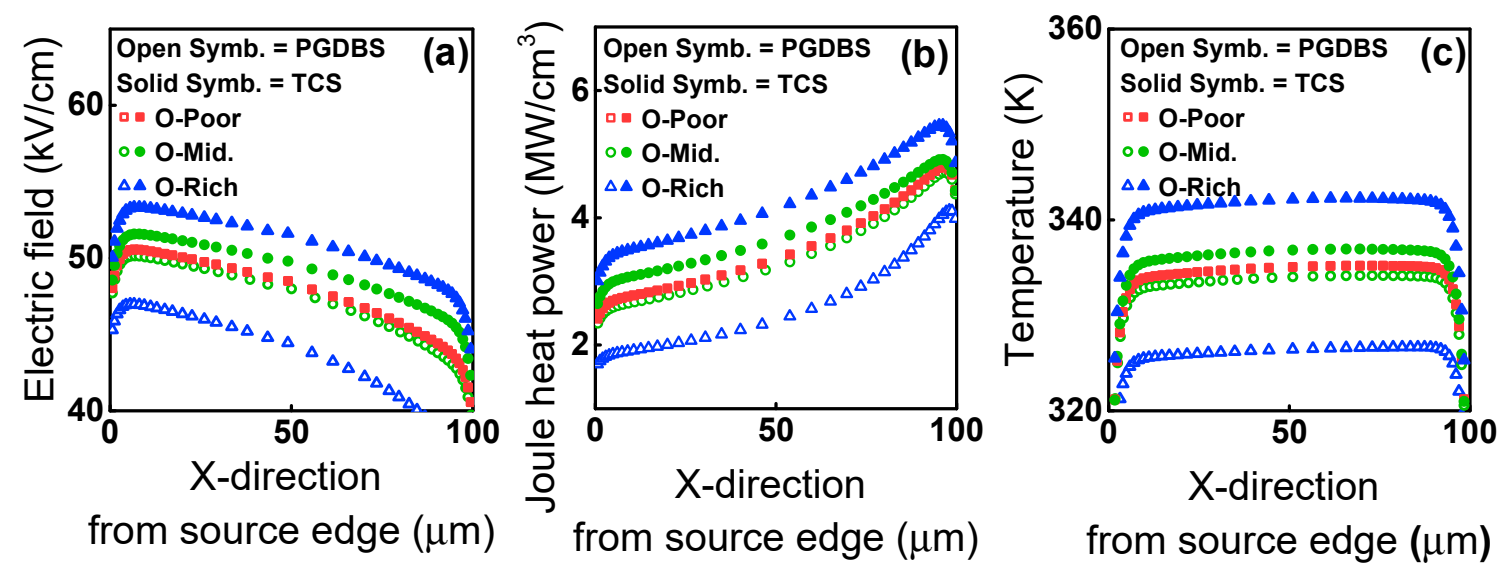

Figure 8. The simulated (a) electric field, (b) Joule heat power, and (c) temperature of the device based on the configuration of $\mathrm{V}_{\mathrm{GS}} / \mathrm{V}_{\mathrm{DS}}$.

Our results suggest that the effect of O-content on CS-induced instability can be explained consistently for all cases considered in this study, i.e., TCS, PGDBS, and PGBS conditions.

\section{Conclusions}

The effect of O-content on CS-induced instability is investigated in bottom-gate a-IGZO TFTs. Under PGDBS and TCS conditions, donor creation was clearly observed in a-IGZO active regions. The observed positive $\Delta \mathrm{V}_{\mathrm{T}}$ was dominated by e-trapping in the GI. Because the O-content affects the GI quality as well as the typical DC-performance parameters, such as $\mathrm{V}_{\mathrm{T}}, \mathrm{SS}$, and $\mu_{\mathrm{FE}}$, stress-induced $\Delta \mathrm{V}_{\mathrm{T}}$ increased with increasing $\mathrm{O}$-content irrespective of the type of stress. For specific O-content, $\Delta \mathrm{V}_{\mathrm{T}}$ increased in the following order: PGDBS $<$ TCS $<$ PGBS, which can be explained by considering a combination of electric field relaxation via donor creation and self-heating-assisted e-trapping. Our results suggest that careful joint optimization of the GI and active layer is indispensable for designing highly stable a-IGZO TFTs. The detailed findings are useful for designing stable current-driving schemes for compensating electrical degradation and for circuits in high-frame-rate displays.

Author Contributions: S.C. and J.-Y.K. contributed equally to this work. Conceptualization, J.-Y.K., S.C. and D.H.K.; Formal analysis, J.-Y.K., S.C. and H.K.; Investigation, D.K. and J.R.; Methodology, J.-Y.K. and S.C.; Writing - original draft, J.-Y.K., S.C. and D.H.K.; Writing - review and editing, S.-J.C., D.M.K. and D.H.K. 
Funding: This work was supported in part of National Research Foundation of Korea (NRF) through the Korean Government, Ministry of Education, Science and Technology (MEST), under Grant 2016R1A5A1012966, Grant 2017R1A2B4006982, Grant 18ZB1800, and Grant 2016M3A7B4909668.

Acknowledgments: The CAD software was supported by SILVACO and IDEC.

Conflicts of Interest: The authors declare no conflict of interest.

\section{References}

1. Tani, R.; Yoon, J.; Yun, S.-I.; Nam, W.; Takasugi, S.; Kim, J.-M.; Park, J.; Kwon, S.; Kim, P.; Oh, C.; et al. 64.2: Panel and Circuit Designs for the World's First 65-inch UHD OLED TV. SID Symp. Dig. Tech. Pap. 2015, 46, 950-953. [CrossRef]

2. Kim, J.; Bang, S.; Lee, S.; Shin, S.; Park, J.; Seo, H.; Jeon, H. A study on H 2 plasma treatment effect on a-IGZO thin film transistor. J. Mater. Res. 2012, 27, 2318-2325. [CrossRef]

3. Chen, W.-T.; Lo, S.-Y.; Kao, S.-C.; Zan, H.-W.; Tsai, C.-C.; Lin, J.-H.; Fang, C.-H.; Lee, C.-C. Oxygen-Dependent Instability and Annealing/Passivation Effects in Amorphous In-Ga-Zn-O Thin-Film Transistors. IEEE Electron. Dev. Lett. 2011, 32, 1552-1554. [CrossRef]

4. Kim, K.A.; Park, M.J.; Lee, W.H.; Yoon, S.M. Characterization of negative bias-illumination-stress stability for transparent top-gate In-Ga-Zn-O thin-film transistors with variations in the incorporated oxygen content. J. Appl. Phys. 2015, 118. [CrossRef]

5. Nomura, K.; Kamiya, T.; Hosono, H. Effects of diffusion of hydrogen and oxygen on electrical properties of amorphous oxide semiconductor, In-Ga-Zn-O. ECS J. Solid State Sci. Technol. 2012, 2, P5-P8. [CrossRef]

6. Moon, Y.-K.; Lee, S.; Kim, D.-H.; Lee, D.-H.; Jeong, C.-O.; Park, J.-W. Application of DC magnetron sputtering to deposition of ingazno films for thin film transistor devices. Jpn. J. Appl. Phys. 2009, 48, 031301. [CrossRef]

7. Nomura, K.; Takagi, A.; Kamiya, T.; Ohta, H.; Hirano, M.; Hosono, H. Amorphous oxide semiconductors for high-performance flexible thin-film transistors. Jpn. J. Appl. Phys. 2006, 45, 4303-4308. [CrossRef]

8. Zhan, R.; Dong, C.; Liu, P.-T.; Shieh, H.-P.D. Influence of channel layer and passivation layer on the stability of amorphous In-Ga-Zn-O thin film transistors. Microelectron. Reliab. 2013, 53, 1879-1885. [CrossRef]

9. Mtangi, W.; Auret, F.D.; Meyer, W.E.; Legodi, M.J.; Janse van Rensburg, P.J.; Coelho, S.M.M.; Diale, M.; Nel, J.M. Effects of hydrogen, oxygen, and argon annealing on the electrical properties of $\mathrm{ZnO}$ and $\mathrm{ZnO}$ devices studied by current-voltage, deep level transient spectroscopy, and Laplace DLTS. J. Appl. Phys. 2012, 111, 094504. [CrossRef]

10. Lee, S.; Park, S.; Kim, S.; Jeon, Y.; Jeon, K.; Park, J.-H.; Park, J.; Song, I.; Kim, C.-J.; Park, Y.; et al. Extraction of subgap density of states in amorphous InGaZnO thin-film transistors by using multifrequency capacitanc-voltage characteristics. Electron. Device Lett. 2010, 31, 231-233.

11. Kim, S.; Jeon, Y.W.; Kim, Y.; Kong, D.; Jung, H.K.; Bae, M.-K.; Lee, J.-H.; Du Ahn, B.; Park, S.Y.; Park, J.-H.; et al. Impact of oxygen flow rate on the instability under positive bias stresses in dc-sputtered amorphous In-Ga-Zn-O thin-film transistors. IEEE Electron. Device Lett. 2012, 33, 62-64. [CrossRef]

12. Kamiya, T.; Nomura, K.; Hirano, M.; Hosono, H. Electronic structure of oxygen deficient amorphous oxide semiconductor a-InGaZnO 4-x: Optical analyses and first-principle calculations. Phys. Stat. Solidi 2008, 5, 3098-3100.

13. Janotti, A.; Van de Walle, C.G. Oxygen vacancies in ZnO. Appl. Phys. Lett. 2005, 87, 122102. [CrossRef]

14. Nomura, K.; Ohta, H.; Takagi, A.; Kamiya, T.; Hirano, M.; Hosono, H. Room-temperature fabrication of transparent flexible thin-film transistors using amorphous oxide semiconductors. Nature 2004, 432, 488-492. [CrossRef] [PubMed]

15. Lee, J.-M.; Cho, I.-T.; Lee, J.-H.; Kwon, H.-I. Bias-stress-induced stretched-exponential time dependence of threshold voltage shift in InGaZnO thin film transistors. Appl. Phys. Lett. 2008, 93, 2-5. [CrossRef]

16. Suresh, A.; Muth, J.F. Bias stress stability of indium gallium zinc oxide channel based transparent thin film transistors. Appl. Phys. Lett. 2008, 92, 033502. [CrossRef]

17. Um, J.G.; Mativenga, M.; Migliorato, P.; Jang, J. Defect generation in amorphous-indium-gallium-zinc-oxide thin-film transistors by positive bias stress at elevated temperature. J. Appl. Phys. 2014, 115, 134502. [CrossRef]

18. Mativenga, M.; Hong, S.; Jang, J. High current stress effects in amorphous-In-Ga-Zn- $\mathrm{O}_{4}$ thin-film transistors. Appl. Phys. Lett. 2013, 102, 1-4. [CrossRef] 
19. Kim, J.I.; Jeong, C.-Y.; Kwon, H.-I.; Jung, K.D.; Park, M.S.; Kim, K.H.; Seo, M.S.; Lee, J.-H. Modeling of asymmetric degradation based on a non-uniform electric field and temperature in amorphous In-Ga-Zn-O thin film transistors. Semicond. Sci. Technol. 2017, 32, 035017. [CrossRef]

20. Lee, D.; Jeong, C.-Y.; Song, S.-H.; Xiao-Shi, J.; Kim, J.I.; Lee, J.-H.; Kwon, H.-I. Asymmetrical degradation behaviors in amorphous In-Ga-Zn-O thin-film transistors under various gate and drain bias stresses. J. Vac. Sci. Technol. B Nanotechnol. Microelectron. Mater. Process. Meas. Phenom. 2015, 33, 011202.

21. Choi, S.; Jang, J.; Kang, H.; Baeck, J.H.; Bae, J.U.; Park, K.-S.; Yoon, S.Y.; Kang, I.B.; Kim, D.M.; Choi, S.-J.; et al. Systematic decomposition of the positive bias stress instability in self-aligned coplanar In-Ga-Zn-O thin-film transistors. IEEE Electron. Dev. Lett. 2017, 38, 580-583. [CrossRef]

22. Choi, S.; Kim, H.; Jo, C.; Kim, H.-S.; Choi, S.-J.; Kim, D.M.; Park, J.; Kim, D.H. The effect of gate and drain fields on the competition between donor-like state creation and local electron trapping in In-Ga-Zn-O thin film transistors under current stress. IEEE Electron. Device Lett. 2015, 36, 1336-1339. [CrossRef]

23. Nahm, H.-H.; Kim, Y.-S.; Kim, D.H. Instability of amorphous oxide semiconductors via carrier-mediated structural transition between disorder and peroxide state. Phys. Stat. Solidi 2012, 249, 1277-1281. [CrossRef]

24. Oh, S.; Baeck, J.H.; Bae, J.U.; Park, K.-S.; Kang, I.B. Effect of interfacial excess oxygen on positive-bias temperature stress instability of self-aligned coplanar In-Ga-Zn-O thin-film transistors. Appl. Phys. Lett. 2016, 108, 141604. [CrossRef]

25. Li, F.; Nathan, A. CCD Image Sensors in Deep-Ultraviolet; Microtechnology and Mems; Springer: Berlin/Heidelberg, Germany, 2005; ISBN 3-540-22680-X.

26. Chen, T.-C.; Chang, T.-C.; Hsieh, T.-Y.; Tsai, M.-Y.; Chen, Y.-T.; Chung, Y.-C.; Ting, H.-C.; Chen, C.-Y. Self-heating enhanced charge trapping effect for In-Ga-Zn-O thin film transistor. Appl. Phys. Lett. 2012, 101, 042101. [CrossRef]

27. Kim, J.I.; Chang, K.S.; Kim, D.U.; Cho, I.-T.; Jeong, C.-Y.; Lee, D.; Kwon, H.-I.; Jin, S.H.; Lee, J.-H. Thermoreflectance microscopy analysis on self-heating effect of short-channel amorphous In-Ga-Zn-O thin film transistors. Appl. Phys. Lett. 2014, 105, 043501. [CrossRef]

28. Urakawa, S.; Tomai, S.; Ueoka, Y.; Yamazaki, H.; Kasami, M.; Yano, K.; Wang, D.; Furuta, M.; Horita, M.; Ishikawa, Y.; et al. Thermal analysis of amorphous oxide thin-film transistor degraded by combination of joule heating and hot carrier effect. Appl. Phys. Lett. 2013, 102, 2011-2015. [CrossRef]

29. Yoshikawa, T.; Yagi, T.; Oka, N.; Jia, J.; Yamashita, Y.; Hattori, K.; Seino, Y.; Taketoshi, N.; Baba, T.; Shigesato, Y. Thermal Conductivity of amorphous Indium-Gallium-Zinc Oxide thin films. Appl. Phys. Express 2013, 6, 021101. [CrossRef]

30. ATLAS User's Manual; Silvaco: Santa Clara, CA, USA, 2018. 